\title{
Irradiation-induced Microstructural Change in Helium-Implanted Single Crystal and Nano-Engineered SiC
}

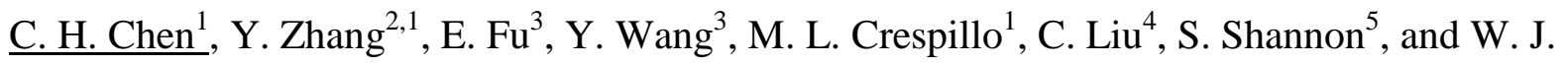
Weber $^{1,2^{*}}$

\begin{abstract}
Microstructural evolution induced by helium implantation and subsequent heavy ion irradiation has been investigated in single crystal and nano-engineered (NE) 3C SiC. Implantation with $65 \mathrm{keV} \mathrm{He}^{+}$ions was performed at $277^{\circ} \mathrm{C}$, and the helium depth distribution was determined by elastic recoil detection analysis (ERDA). Transmission electron microscopy (TEM) could not resolve the presence of bubbles in any of the helium-
\end{abstract}


23 implanted single crystal SiC. However, helium platelets and small dislocation loops ( $50 \mathrm{~nm}$

24 in diameter) were observed in the single crystal sample with the highest implantation fluence

25 after 1 hour annealing at $700^{\circ} \mathrm{C}$. Following irradiation with $9 \mathrm{MeV} \mathrm{Au}^{3+}$ ions at $700^{\circ} \mathrm{C}$, no

26 bubbles were observed in the helium-implanted single crystal $\mathrm{SiC}$, regardless of helium

27 fluence. For the helium-implanted NE SiC, subsequent irradiation with $9 \mathrm{MeV}$ Au ions to a

28 dose of $10 \mathrm{dpa}$ at $700^{\circ} \mathrm{C}$ resulted in the formation and growth of bubbles, and a bimodal

29 helium bubble size distribution was observed at the highest helium concentration (8000 appm)

30 in the NE SiC. 


\section{Introduction}

Because of its mechanical stability under high-energy neutron irradiation and high temperature [1], silicon carbide ( $\mathrm{SiC}$ ) has great potential as a structural material in advanced nuclear energy systems. For fission reactors, $\mathrm{SiC}$ is proposed as the fuel component to retain fission products, and the He/dpa production rate in $\mathrm{SiC}$ is reported to be $2.5 \mathrm{appm} / \mathrm{dpa}$ for typical fission neutron spectra [2]. However, as a structural material in fusion reactors, SiC will be exposed to much higher dose and helium production rates [3] .

The SiC crystal structure exhibits high thermal conductivity, high-temperature stability, chemical inertness, and good resistance against irradiation [4,5]. However, since deuterium-tritium (D-T) fusion reactions will produce $14.1 \mathrm{MeV}$ neutrons, the high $(\mathrm{n}, \alpha)$ cross-section of $\mathrm{SiC}$ will yield higher helium production rates, up to $130 \mathrm{appm} / \mathrm{dpa}$ near the first wall of a fusion reactor [1], which will promote the formation of cavities and gas bubbles due to the low solubility and diffusivity of helium in SiC. Accumulation of irradiationinduced cavities or bubbles will lead to significant volume swelling. In addition, radiationinduced defects and dislocation loops may lead to post-yield strain-hardening effects, which alter the mechanical properties $[6,7]$.

In the absence of suitable fission or fusion neutron test facilities capable of achieving the high neutron fluences expected in advanced reactors, ion implantation and irradiation techniques can be used to investigate the effects of high helium content and high irradiation doses in SiC. Ion implantation with helium ions results in both the buildup of a helium concentration profile and the production and accumulation of Frenkel defects that can lead to amorphization, dislocation loop formation and chemical disordering, as well as drive the nucleation and growth of helium bubbles. Despite intensive ion irradiation studies of fusion 
materials $[8,9]$, the mechanisms of damage formation, defect accumulation, and helium trapping are not well understood, particularly with regard to gas bubble aggregation. Therefore, a fundamental understanding of helium implantation and irradiation damage behavior in $\mathrm{SiC}$, and the complex processes involved, where the production and subsequent evolution of defects play an important role, is of considerable technological importance for the development of advanced fission and fusion reactors $[10,11]$.

In addition, it was previously reported that nano-engineered $\mathrm{SiC}$ (NE SiC) with high stacking fault densities could effectively enhance defect recombination and annihilation rates under irradiation [12-14]. Therefore, a comparison study of irradiation-induced defect behavior in nano-engineered $\mathrm{SiC}$ and single crystal $\mathrm{SiC}$ is important for improving the understanding of irradiation damage processes and developing radiation tolerant structural materials for fusion reactors [11].

In this study, helium implantation and subsequent heavy-ion irradiation are performed to investigate the irradiation response of single crystal and nano-engineered SiC. Elastic recoil detection analysis (ERDA) is used to quantify the implanted helium concentration profile, since it is ideally suited for the analysis of helium in heavier targets, such as SiC. Furthermore, ERDA has better mass resolution than Rutherford backscattering spectrometry (RBS) to detect light elements without background interference [15-17]. The helium depth distribution determined from the ERDA spectrum is compared with the prediction from the Stopping and Range of Ions in Matter (SRIM) simulations (version 2012) [18,19]. Crosssection transmission electron microscopy (TEM) analysis is used to determine the size and local densities of bubbles and dislocation loops. 


\section{Experimental details.}

The materials used for this research are single crystal 3C SiC thin film, with a

thickness of $1000 \mathrm{~nm}$ on a Si substrate (CVD process by NOVA SiC, France), and NE SiC films that contain a high density of <111>-type stacking faults (spacing of 1 to $2 \mathrm{~nm}$ ) within columnar grains of 100 to $300 \mathrm{~nm}$ size grown along the [111] direction. The NE SiC films were grown on $\mathrm{Si}$ (100) wafers by low-pressure chemical vapor deposition with an average film thickness of $532 \mathrm{~nm}$. Details of the processing technique for the $\mathrm{NE} \mathrm{SiC} \mathrm{are} \mathrm{provided}$ elsewhere [12]

The helium ion implantations were performed using the $200 \mathrm{kV}$ ion-implanter at Los Alamos National Laboratory (LANL) [20]. The ERDA measurements and high-dose heavy ion irradiations were performed using the 3.0 MV Pelletron Tandem Accelerator in the Ion Beam Materials Laboratory at the University of Tennessee (UT-IBML) [21].

Samples of the single crystal $3 \mathrm{C} \mathrm{SiC}$ were implanted with $65 \mathrm{keV} \mathrm{He}^{+}$ions at $7^{\circ}$ off the surface normal to avoid channelling conditions, and the NE SiC samples were implanted with $65 \mathrm{keV} \mathrm{He}^{+}$ions along the surface normal. Both types of $\mathrm{SiC}$ samples were implanted to three helium ion fluences $\left(1 \times 10^{15}, 3 \times 10^{15}\right.$ and $\left.1 \times 10^{16} \mathrm{~cm}^{-2}\right)$ at $277^{\circ} \mathrm{C}$, above the critical temperature for amorphization [22,23], to avoid irradiation-induced-amorphization. The helium depth profiles and damage profiles for both the $\mathrm{He}^{+}$and $\mathrm{Au}^{+}$ion irradiation are determined using the SRIM code $[18,19]$, and the peak in helium concentration is predicted to be at a depth of $350 \mathrm{~nm}$ from the surface, as illustrated in Fig. 1. The ERDA measurements were performed at the UT-IBML in a high-vacuum chamber $\left(1.3 \times 10^{-5} \mathrm{~Pa}\right)$ to confirm the helium concentration profile in the single crystal $3 \mathrm{C} \mathrm{SiC}$ specimen implanted at the highest helium fluence $\left(1 \times 10^{16} \mathrm{~cm}^{-2}\right)$. In the ERDA measurement, an $11 \mathrm{MeV}$ beam of $\mathrm{O}^{4+}$ ions 
impinges on the specimen at $75^{\circ}$ off the surface normal, and a mylar foil with thickness $9.6 \times 10^{19}$ atom $/ \mathrm{cm}^{2}$ (i.e. $10 \mu \mathrm{m}$ ) is placed in front of a $\mathrm{Si}$ detector to block the forward scattered or recoiled particles, except helium (see Fig. 2 (a)). The depth profile is acquired by converting the channel numbers to depth (nm). The helium concentration profile in single crystal 3C SiC determined from the ERDA spectrum is shown in Fig. 2 (b). The peak helium concentration is about $0.8 \%$ (8000 appm), and helium distribution agrees well with the SRIM2012 [18,19] prediction.

To compare and verify the critical dose for helium bubble formation under far-fromequilibrium irradiation conditions, subsequent irradiation with $9 \mathrm{MeV} \mathrm{Au}^{3+}$ ions was carried out in a multi-purpose target chamber in the UT-IBML facility. The dose in dpa is determined using SRIM2012, assuming a density of $3.21 \mathrm{~g} / \mathrm{cm}^{3}$ and displacement energies of $20 \mathrm{eV}$ and $35 \mathrm{eV}$ for the $\mathrm{C}$ and $\mathrm{Si}$ sublattices, respectively [24]. In this study, irradiation to an ion fluence of $7.75 \times 10^{15} \mathrm{~cm}^{-2}$ was performed to produce a low gradient, average damage profile of $10 \mathrm{dpa}$ at a depth of 200 to $500 \mathrm{~nm}$ from the surface, as shown in Fig. 1. A uniform rastered beam, with scanning frequencies of 517 and $64 \mathrm{~Hz}$ for the horizontal and vertical direction, respectively, and a constant particle flux of $2.3 \times 10^{12} \mathrm{~cm}^{-2} \mathrm{~s}^{-1}$ (current density of $11.1 \mathrm{nA} / \mathrm{mm}^{2}$ ) were used. A glass scintillator and a CCD camera, placed through a silica viewport on the multipurpose chamber, were used to accurately locate the ion beam on the sample.

The $9 \mathrm{MeV} \mathrm{Au}{ }^{3+}$ irradiations were performed at a temperature of $700^{\circ} \mathrm{C}$ under high vacuum conditions $\left(4 \times 10^{-5} \mathrm{~Pa}\right)$. The temperature of the sample during irradiation, as well as during thermal annealing, was monitored and controlled using the HRN (LPS-800-1) heater controller from Thermionics Northwest Inc. [25]. The main thermocouple was located on the sample, and an additional one was connected to the sample holder, with the aim of accurately 
controlling the temperature during irradiation and thermal annealing processes.

During irradiation at $700^{\circ} \mathrm{C}$, a region of each helium-implanted sample was masked to retain un-irradiated areas in order to investigate the separate effects of thermal annealing on helium migration and bubble evolution in the absence of high dose irradiation. Such an approach ensures similar thermal conditions and provides a more reliable comparison of helium evolution at high temperature with and without heavy ion irradiation. The crosssectional TEM samples were then prepared by mechanical polishing. Additional ion milling (5 to $3 \mathrm{keV} \mathrm{Ar}^{+}$ions at an angle of $85^{\circ}$ off the surface normal) was performed as necessary to achieve an electron transparent region in the specimens. A ZEISS Libra 200 HT FE MC highresolution transmission-electron-microscope (HRTEM), operated at $200 \mathrm{kV}$ and equipped with a Gatan imaging filter (GIF 863 Tridiem), was employed to analyse the microstructure of the SiC samples. All images were recorded in a slightly underfocused condition, (Scherzer defocus, with defocus value of about $50 \mathrm{~nm}$ ). In order to confirm the presence of small bubbles, a bright-field through-focal images series was recorded in Fig. 3 and bubbles as small as few nanometres could be detected under the defocused conditions.

\section{Experimental results and analysis.}

\subsection{Single crystal 3C SiC.}

A typical cross-sectional bright field (BF) TEM image from the single crystalline sample implanted to the highest helium fluence $\left(1 \times 10^{16} \mathrm{~cm}^{-2}\right)$ is shown in Fig. 4. A wellordered crystal structure with a few stacking faults is observed; even in the highest helium concentration region, the $\mathrm{SiC}$ still remains crystalline. In the single crystal sample with the highest helium implantation fluence, no bubbles or cavities could be resolved. Consequently, the samples with lower helium fluences were reserved for subsequent high temperature 
heavy-ion irradiation.

In order to understand helium bubble formation and growth mechanisms, the single crystal $\mathrm{SiC}$ specimen with the highest helium fluence $\left(1 \times 10^{16} \mathrm{~cm}^{-2}\right)$ was annealed at $700^{\circ} \mathrm{C}$ for 1 hour. Microstructural TEM images are shown in Fig. 5. The thermal annealing of the sample implanted with up to 8000 appm helium resulted in the formation of helium platelets and dislocation loops with diameters of about $50 \mathrm{~nm}$. Helium platelets are observed in the specimen at a depth of $370 \mathrm{~nm}$ from the surface, which agrees well with the depth of the peak helium concentration predicted by SRIM2012. This suggests that the formation of helium platelets in the $3 \mathrm{C} \mathrm{SiC}$ is caused by thermal diffusion of implanted helium and possibly residual implantation-induced defects during annealing.

Subsequent heavy-ion irradiation at $700^{\circ} \mathrm{C}$ was performed to investigate irradiationinduced gas bubble nucleation and growth. The series of single crystal 3C SiC samples, with different pre-implanted helium fluences, were further irradiated to $10 \mathrm{dpa}$ at $700^{\circ} \mathrm{C}$ with 9 $\mathrm{MeV} \mathrm{Au}{ }^{3+}$ ions (Fig. 1). The typical TEM microstructures observed in these samples are shown in Fig. 6. No obvious helium bubbles are observed in the samples with peak helium concentrations from 800 to 8000 appm. Although helium has comparable effectiveness for inducing blistering and exfoliation at much higher implantation fluences [26], surface blistering was not observed, as expected, for the helium implanted specimens in this study.

\subsection{Nano-engineered (NE) SiC.} 4

TEM micrographs of the NE SiC implanted with helium ions are shown in Fig. 7. While the high stacking fault densities are clearly observed, the formation of helium bubbles is inconclusive. Compared to the implanted single crystal specimens, the NE SiC contains more defects and provides more nucleation sites that may promote the formation of helium 
bubbles. Although a bright field through focal images series was recorded, the bubbles were too small (sub-nm) and too few to quantify either size or density with any degree of certainty, and it was only in the as-implanted specimens, with helium fluences of $3 \times 10^{15} \mathrm{~cm}^{-2}(2400$ appm at peak) and higher, that a few sub-nm bubbles were indicated.

Typical TEM micrographs from the helium-implanted NE SiC specimens after annealing for 68 minutes at $700^{\circ} \mathrm{C}$ are shown in Fig. 8. In contrast to the helium-implanted single crystal $\mathrm{SiC}$, more evidence for sub-nm helium bubbles was observed in the heliumimplanted NE SiC specimens after annealing, but could not be quantified at this stage of bubble evolution. This could support the hypothesis that bubble nucleation is more probable in the NE SiC, but this is still not clearly demonstrated. Similar to the enhanced diffusion of point defects in this $\mathrm{NE} \mathrm{SiC}[12,13,27]$, helium may also be more mobile and constrained to two-dimensional migration (parallel to the nano-layered faults), and the two-dimensional diffusion of helium and point defects should enhance nucleation. While helium bubbles are not clearly observable in Fig. 8, the high density of stacking faults appears relatively unchanged due to thermal annealing at $700^{\circ} \mathrm{C}$.

To compare the irradiation-induced helium bubble formation behavior in NE SiC with single crystal $\mathrm{SiC}$, the helium implanted $\mathrm{NE} \mathrm{SiC}$ samples were also irradiated to $10 \mathrm{dpa}$ with $9 \mathrm{MeV} \mathrm{Au}{ }^{3+}$ ions at $700^{\circ} \mathrm{C}$. Helium bubbles of different sizes are clearly observed over a wide range of depth, as shown in Fig. 9, and the high density of stacking faults is generally retained. A quantitatively summary of bubble size and density is provided in Table 1.

The helium bubbles observed in the Au-irradiated NE SiC show a bimodal size distribution for specimens implanted to $\mathrm{He}^{+}$fluences of $3 \times 10^{15} \mathrm{~cm}^{-2}$ and higher. Larger helium bubbles are observed following irradiation of the helium implanted regions to high doses, especially at grain boundaries. The average diameters of the helium bubbles within the 
203

204

205

206

207

208

209

210

211

212

213

214

215

216

217

219

220

221

222

223

224

225

226

227

bimodal size distribution are about $1.75 \mathrm{~nm}$ and $3.75 \mathrm{~nm}$ for the highest He implantation fluence of $1 \times 10^{16} \mathrm{~cm}^{-2}$ (Fig. 10 (c) and Table 1).

Clearly, the growth of helium bubbles at elevated temperature is enhanced by the defects produced from irradiation with $\mathrm{Au}^{3+}$ ions to 10 dpa. In Fig. 9, helium bubbles at grain boundaries and within the grains are observed in the Au-irradiated specimens for all helium concentrations. These results demonstrate that helium can migrate and nucleate bubbles at preferential sites in the NE SiC; furthermore, bubble growth is enhanced by the continuous production of irradiation-induced defects. Average bubble sizes and densities are summarized in Table 1. The average diameters of the helium bubbles are $1.7 \pm 0.5 \mathrm{~nm}, 1.7 \pm 0.9 \mathrm{~nm}$ and $2.4 \pm 1.0 \mathrm{~nm}$, respectively, from the lower helium concentration $\left(1 \times 10^{15} \mathrm{~cm}^{-2}\right)$ to the higher helium concentration $\left(1 \times 10^{16} \mathrm{~cm}^{-2}\right)$. These results are in good agreement with the normalized bubble size distributions shown in Fig. 10. For bubble diameters smaller than $1 \mathrm{~nm}$, due to the uncertainty of the measurements, the associated bubble size regime is shown with dashed lines; however, this size regime fits well with the measured size distributions shown. Most of the bubbles are observed at the grain boundaries, which is not surprising, since grain boundaries can act as strong sinks for both the implanted helium and irradiation-induced defects. The bubbles at grain boundaries are larger in size (varying from 1 to $10 \mathrm{~nm}$ ) compared with the average size within the grains.

\section{Discussion.}

\subsection{Single crystal 3C SiC behavior}

Our observation for $\mathrm{He}^{+}$implanted 3C SiC, shown in Fig. 4, is consistent with Zinkle's results [26] who reported that, at room temperature and $650^{\circ} \mathrm{C}$, the threshold helium concentrations for bubble formation in $\mathrm{SiC}$ are 1.7\% (17000 appm) and 2\% (20000 appm), respectively. Hence, no helium bubbles are expected in the single crystal $3 \mathrm{C} \mathrm{SiC}$ implanted 
with helium to a fluence of $1 \times 10^{16} \mathrm{~cm}^{-2}\left(\sim 8000\right.$ appm at implanted helium peak) at $277^{\circ} \mathrm{C}$.

The helium-induced damage in the $3 \mathrm{C} \mathrm{SiC} \mathrm{did} \mathrm{not} \mathrm{have} \mathrm{a} \mathrm{pronounced} \mathrm{effect} \mathrm{on} \mathrm{the} \mathrm{formation}$ of helium bubbles, although a low density of large dislocation loops ( $\sim 50 \mathrm{~nm}$ diameter $)$ are observed in the mid-range region about $300 \mathrm{~nm}$ from the implantation surface (Fig. 6(c)). Figure 5 shows the microstructure of $\mathrm{SiC}$ in the helium peak region after one hour thermal annealing at $700^{\circ} \mathrm{C}$. Cavities or bubbles observed in the helium implanted region are highly localized in this region and preferentially associated with dislocation loops lying on the $\{11$ $1\}$ and $\left\{\begin{array}{lll}1 & 1 & 0\end{array}\right\}$ habit planes. The cavities appear as platelets coinciding with the loops. Hence, the annealing temperature of $700^{\circ} \mathrm{C}$ is insufficient for longer-range helium diffusion, but local precipitation is possible. This is in agreement with Miro et al. [28], who found thermally-activated helium migration in single crystal $\mathrm{SiC}$ only occurs above $1100^{\circ} \mathrm{C}$.

\subsection{Nano-engineered (NE) SiC behavior:}

In contrast to the behavior in single crystal $3 \mathrm{C} \mathrm{SiC}$, helium bubbles with measurable sizes are formed at high-temperature in irradiated NE SiC. This can be understood, in part, as due to a higher number of nucleation sites provided by the high-density stacking faults and grain boundaries. While sub-nm helium bubbles are not resolvable with certainty in the asimplanted and annealed samples, within the resolution limits of the microscope, bubbles of about $1 \mathrm{~nm}$ size and larger are observed following heavy-ion irradiation at $700^{\circ} \mathrm{C}$ to $10 \mathrm{dpa}$. Since the implanted $\mathrm{Au}^{3+}$ ion peak is located far (in the substrate) from the helium implanted region, possible effects related to implanted $\mathrm{Au}$ ions are negligible, and only the defects created along the Au ion path will contribute to the nucleation and growth of helium bubbles. Under high-dose irradiation at $700^{\circ} \mathrm{C}$, interstitial loops readily form in $\mathrm{SiC}$ [29], leaving a supersaturation of vacancies; these vacancies and the more mobile helium can interact and precipitate to promote bubble nucleation and growth. Because the size of the helium bubbles 
253

254

255

256

257

258

259

260

261

262

263

264

265

266

267

268

269

270

271

272

273

274

(from 1 to $10 \mathrm{~nm}$ ) formed at grain boundaries is significantly larger than the average helium bubble size inside the grains (from 1 to $2 \mathrm{~nm}$ ), the grain boundaries enhance bubble growth by providing preferential sink sites for defects and helium. Moreover, bubble migration might also be enhanced along grain boundaries. The relative increase in bubble size, from sub-nm for thermal annealing to $>1 \mathrm{~nm}$ under irradiation, may suggest an irradiation-induced bubble coarsening process, as proposed by Trinkaus et al [30], but further experimental work is needed to confirm the presence of an irradiation-induced coarsening process at this temperature.

Because the most probable positions for helium atoms to occupy in a lattice are substitutional (helium atoms in vacancies) and interstitial sites, the dominant migration mode (including preferential position effects) depends not only on temperature, but also on the interaction with irradiation-induced defects, such as vacancies that act as traps for helium atoms to form helium-vacancy clusters. When the vacancy concentration is significantly increased by irradiation, the substitutional sites are preferred due to the strong binding of helium atoms to vacancies. For helium bubble formation, both substitutional and interstitial helium defects may be involved. The substitutional helium-vacancy complexes act either as a bubble nuclei or sources of helium from detrapping mechanisms, and the interstitial helium provides a flux of helium to nucleation sites. The migration energies for interstitial helium have been estimated for bulk $\mathrm{SiC}$ to be in the range from $1.1 \mathrm{eV}$ [31] to $1.5 \mathrm{eV}$ [32], and the detrapping energy of helium from helium-vacancy clusters is about $3.2 \mathrm{eV} \mathrm{[32].} \mathrm{However,} \mathrm{the}$ migration and de-trapping energies for interstitial defects in NE SiC are significantly decreased relative to bulk $\mathrm{SiC}$ [27], and similar behaviour might occur for interstitial helium and vacancies. The supersaturation of vacancies near bubble nuclei and the possible migration of vacancies in $\mathrm{NE} \mathrm{SiC} \mathrm{should} \mathrm{promote} \mathrm{the} \mathrm{growth} \mathrm{of} \mathrm{bubbles} \mathrm{under} \mathrm{irradiation}$ over the thermal nucleation of bubbles, leading to larger bubbles, lower bubble densities and 
bimodal distribution at later growth stages. The grain boundaries can preferentially stabilize the bubble nuclei and enhance bubble growth by trapping helium atoms [33], which agrees with Chen et al.'s and Keng et al.'s observations of helium bubble aggregation in SiC $[34,35]$.

We observe that the average diameter of helium bubbles after high temperature $\mathrm{Au}^{3+}$ ions irradiation is much greater than that for the sub-nm bubbles tentatively identified in specimens processed by thermal annealing. Under non-equilibrium irradiation environment at high temperature $\left(700^{\circ} \mathrm{C}\right)$, the helium bubble coarsening is strongly enhanced by $\mathrm{Au}^{3+}$ ion irradiation. Although thermal annealing might also enhance bubble coarsening over much longer times or at higher temperatures [36], the thermal growth of helium bubbles is not as effective as irradiation-induced growth under a constant defect production rate.

Due to the resolution limitations of the TEM measurements, the tentative number of sub-nm bubbles estimated from the TEM images is included only as a dashed line in the size distributions shown in Fig. 10. A clear transition in bubble size distribution is observed with increasing $\mathrm{He}^{+}$ion fluence. At a low helium fluence of $1 \times 10^{15} \mathrm{~cm}^{-2}$, the helium bubbles have a Lorentzian distribution that is peaked around $1.65 \mathrm{~nm}$ (Fig. 10 (a)). At the intermediate helium fluence $\left(3 \times 10^{15} \mathrm{~cm}^{-2}\right)$, where the most probable bubble size is around $1.65 \mathrm{~nm}$ (Fig. 10 (b)), a Gaussian distribution provides a best fit to the bubble distribution; however, the presence of a few large bubbles suggest the start of a transition to a bimodal distribution. At the highest helium fluence $\left(1 \times 10^{16} \mathrm{~cm}^{-2}\right)$, helium bubbles further evolve and exhibit a bimodal size distribution. As shown in Fig. 10 (c), a well-defined bimodal distribution is evident, with the most probable sizes at $1.75 \mathrm{~nm}(25 \%)$ and $3.75 \mathrm{~nm}(15 \%)$. Such a bimodal distribution is only found under irradiation when the helium concentration is large enough to produce substantial bubble growth. For specimens at lower helium fluences, the helium concentration is insufficient to promote the growth of larger bubbles (Fig. 10 (a)). (See Table 1 for more details). 
303

304

305

306

307

The average stacking fault spacings under the different implantation and irradiation conditions have been determined and are summarized in Table 2. The stacking fault spacing exhibits a weak dependence on helium implantation fluence. Although stacking faults in SiC are low-energy configurations, the nanoscale distances between the layers of stacking fault structures remained less than $2 \mathrm{~nm}$, even after high temperature irradiation with $\mathrm{Au}^{3+}$ ions to $10 \mathrm{dpa}$. Thus, a high radiation tolerance and stability of the $\mathrm{NE} \mathrm{SiC}$ at $700^{\circ} \mathrm{C}$ is clearly demonstrated.

\section{Conclusions.}

In the present study, defect production and helium gas bubble formation are studied in both single crystal 3C SiC and nano-engineered (NE) SiC. The crystalline structure of the 3C $\mathrm{SiC}$ single crystal is retained after $65 \mathrm{keV}$ helium implantation at $277^{\circ} \mathrm{C}$ and $10 \mathrm{dpa} \mathrm{Au}^{3+}$ irradiation at $700^{\circ} \mathrm{C}$. Visible planar defects form in the helium implanted single crystal SiC after $700^{\circ} \mathrm{C}$ annealing. However, no cavities are observed in single crystal 3C SiC following Au ion irradiation at $700^{\circ} \mathrm{C}$.

In contrast to the behavior in single crystals, irradiation-induced bubble growth occurs in the $\mathrm{NE} \mathrm{SiC} \mathrm{under} \mathrm{irradiation} \mathrm{with} \mathrm{Au}^{3+}$ ions at $700^{\circ} \mathrm{C}$ to $10 \mathrm{dpa}$. Bubble growth results in a bimodal bubble size distribution at the higher helium implantation fluences. Larger bubbles (with diameters of 1 to $10 \mathrm{~nm}$ ) form preferentially at grain boundaries, which may result in degradation of strength in the NE SiC. The high density of stacking faults is retained after heavy ion irradiation at high temperature, suggesting that this nanostructure is somewhat radiation tolerant.

\section{Acknowledgements.}

This work was supported by the DOE Office of Nuclear Energy, Nuclear Energy University Programs. 


\section{References.}

[1] L. L. Snead, R. H. Jones, A. Kohyama, P. Fenici, J. Nucl. Mater. 233-237 (1996) 26.

[2] H. L. Heinisch, L. R. Greenwood, W. J. Weber, R. E. Williford, J. Nucl. Mater. 327 (2004) 175.

[3] C. H. Wu, C. Alessandrini, J. P. Bonal, J. W. Davis, A. A. Haasz, W. Jacob, A. Kallenbach, J. Keinonen, P. Kornejew, R. Moormann, V. Philipps, J. Roth, F. Scaffidi-Argentina, H. Würz, Fus. Engin. and Design 56-57 (2001) 179.

[4] M. Bockstedte, A. Marini, O. Pankratov, A. Rubio, Phys. Rev. Lett. 105 (2010) 026401.

[5] L. Giancarli, J. P. Bonal, A. Caso, G. Le Marois, N. B. Morley, J. F. Salavy, Fus. Engin. and Design 41 (1998) 165.

[6] S. J. Zinkle, Fus. Sci. and Tech. 47 (2005) 821.

[7] H. B. Zhou, S. Jin, Y. Zhang, G. H. Lu, F. Liu, Phys. Rev. Lett. 109 (2012) 135502.

[8] F. Gao, W. J. Weber, Phys. Rev. B 66 (2002) 024106.

[9] P. Jung, H. Klein, J. Chen, J. Nucl. Mater. 283-287 (2000) 806.

[10] Y. Liu, G. Wang, S. Wang, J. H. Yang, L. Chen, X. B. Qin, B. Song, B. Y. Wang, X. L. Chen, Phys. Rev. Lett. 106 (2011) 087205.

[11] T. Nozawa, T. Hinoki, A. Hasegawa, A. Kohyama, Y. Katoh, L. L. Snead, C.H. Henager Jr., J. B. J. Hegeman, J. Nucl. Mater. 386-388 (2009) 622.

[12] Y. Zhang, M. Ishimaru, T. Varga, T. Oda, C. Hardiman, H. Xue, Y. Katoh, S. Shannone and W. J. Weber, Physical Chemistry Chemical Physics 14 (2012) 13429.

[13] M. Ishimaru, Y. Zhang, S. Shannon, W. J. Weber, Appl. Phys. Lett. 103 (2013) 033104.

[14] G. Ackland, Science 327 (2010) 1587.

[15] J. Jensen, G. Possnert, and Y. Zhang, Journal of Physics: Conference Series 100 (2008) 012041.

[16] L. C. Feldman, J. W. Mayer, S. T. Picraux, , Materials Analysis by lon Channeling, Academic Press 1982.

[17] L. C. Feldman, and J. W. Mayer, Fundamentals of Surface and Thin Film Analysis, North-Holland, 1986.

[18] J. F. Ziegler, M. D. Ziegler, J. P. Biersack, Nucl. Inst. Methods Phys. Res. B 268 (2010) 1818.

[19] J. F. Ziegler, SRIM 2012 Software code. SRIM -The Stopping and Range of lons in Matter, <www.srim.org>, (2012).

[20] Los Alamos National Laboratory, LANL, <http://www.lanl.gov/mst/ibml/>, (2013).

[21] Ion Beam Materials Laboratory: UT-IBML Knoxville, <http://ibml.utk.edu/index.html $>$, (2012).

[22] W. Jiang, Y. Zhang, W. J. Weber, Phys. Rev. B 70 (2004) 165208.

[23] Y. Zhang, W. J. Weber, W. Jiang, C. M. Wang, V. Shutthanandan, and A. Hallén, J. Appl. Phys. 95 (2004) 4012.

[24] R. Devanathan, W. J. Weber, F. Gao, J. Appl. Phys. 90 (2001) 2303.

[25] Thermionics Northwest Inc., <http://www.thermionics.com/En-Us/Desktop/View/>, (2013).

[26] S. J. Zinkle, Nucl. Inst. Methods Phys. Res. B 286 (2012) 4.

[27] L. Jamison, M. Zheng, S. Shannon, T. Allen, D. Morgana, I. Szlufarska, J. Nucl. Mater. 445 (2014) 181.

[28] S. Miro, J.M. Costantini, J. Haussy, L. Beck , S. Vaubaillon, S. Pellegrino , C. Meis , J. J. Grob , Y. Zhang, W. J. Weber, J. Nucl. Mater. 415 (2011) 5.

[29] S. Kondo, T. Hinoki, A. Kohyama, Mat. Transact. 46 (2005) 1388.

[30] H. Trinkaus, B. N. Singh, J. Nucl. Mater. 323 (2003) 229.

[31] D. Jung, J. Nucl. Mater. 191-194 (1992) 377.

[32] E. Oliviero, A. van Veen, A. V. Fedorov, M. F. Beaufort, J. F. Barbot, Nucl. Inst. Methods Phys. Res. B 186 (2002) 223.

[33] L. Vincent, T. Sauvage, G. Carlot, P. Garcia, G. Martin, M.F. Barthe, P. Desgardin, Vacuum 83 (2009) 536. 
376

377

378

379

380

381

382

383
[34] K. F. Chen, C. H. Chen, Z. H. Zeng, F. R. Chen and J. J. Kai, Progress in Nuclear Energy 57 (2012) 46.

[35] H. T. Keng, S. W. Li, S. W. Wu, J. J. Kai, F. R. Chen, Y. Katoh, A. Kohyama, J. Nucl. Mater. 367370 (2007) 753.

[36] C. H. Zhang, S. E. Donnelly, V. M. Vishnyakov, and J. H. Evans J. Appl. Phys. 94 (2003) 6017. 


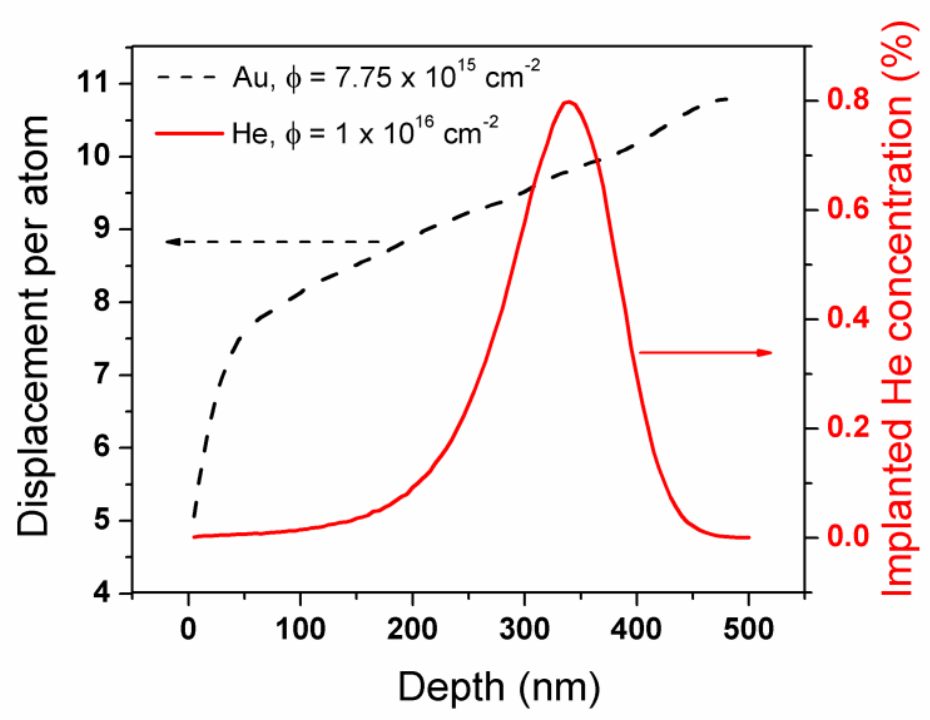

Fig. 1 SRIM predicted damage profile (in displacements per atoms) and implanted helium concentration for the $\mathrm{SiC}$ irradiated by $9 \mathrm{MeV} \mathrm{Au}$ ions for a fluence of $7.75 \times 10^{15} \mathrm{~cm}^{-2}$ (dashed line), and $65 \mathrm{keV} \mathrm{He}^{+}$ions for a fluence of $1 \times 10^{16} \mathrm{~cm}^{-2}$ (solid line).

(b)

(a)

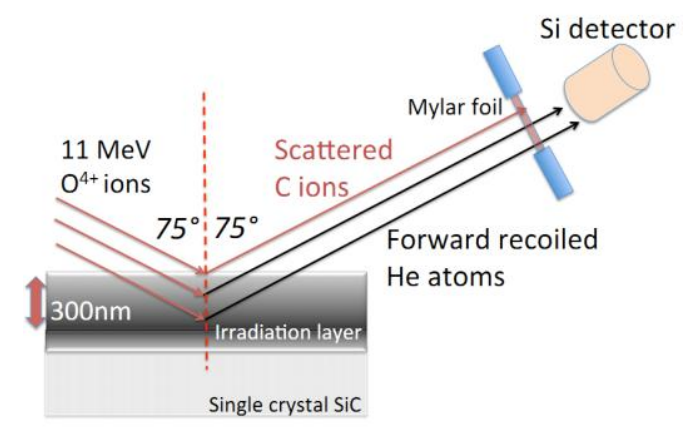

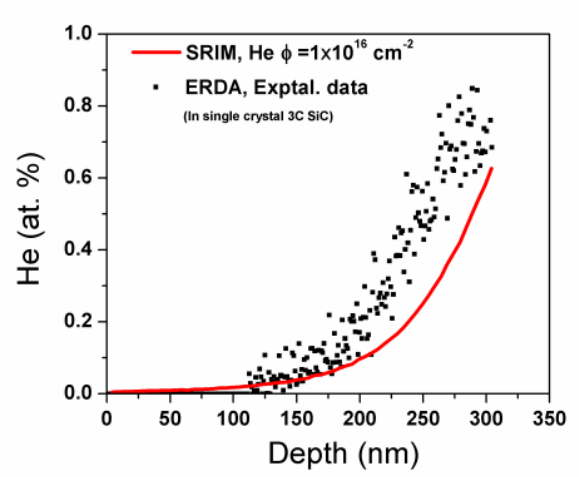

Fig. 2. (a) ERDA experimental configuration and (b) Helium depth profile in single crystal 3C SiC $\left(1 \times 10^{16} \mathrm{~cm}^{-2}\right)$ from the ERDA experiment (dots) and the SRIM2012 prediction (red solid line) $[18,19]$. 

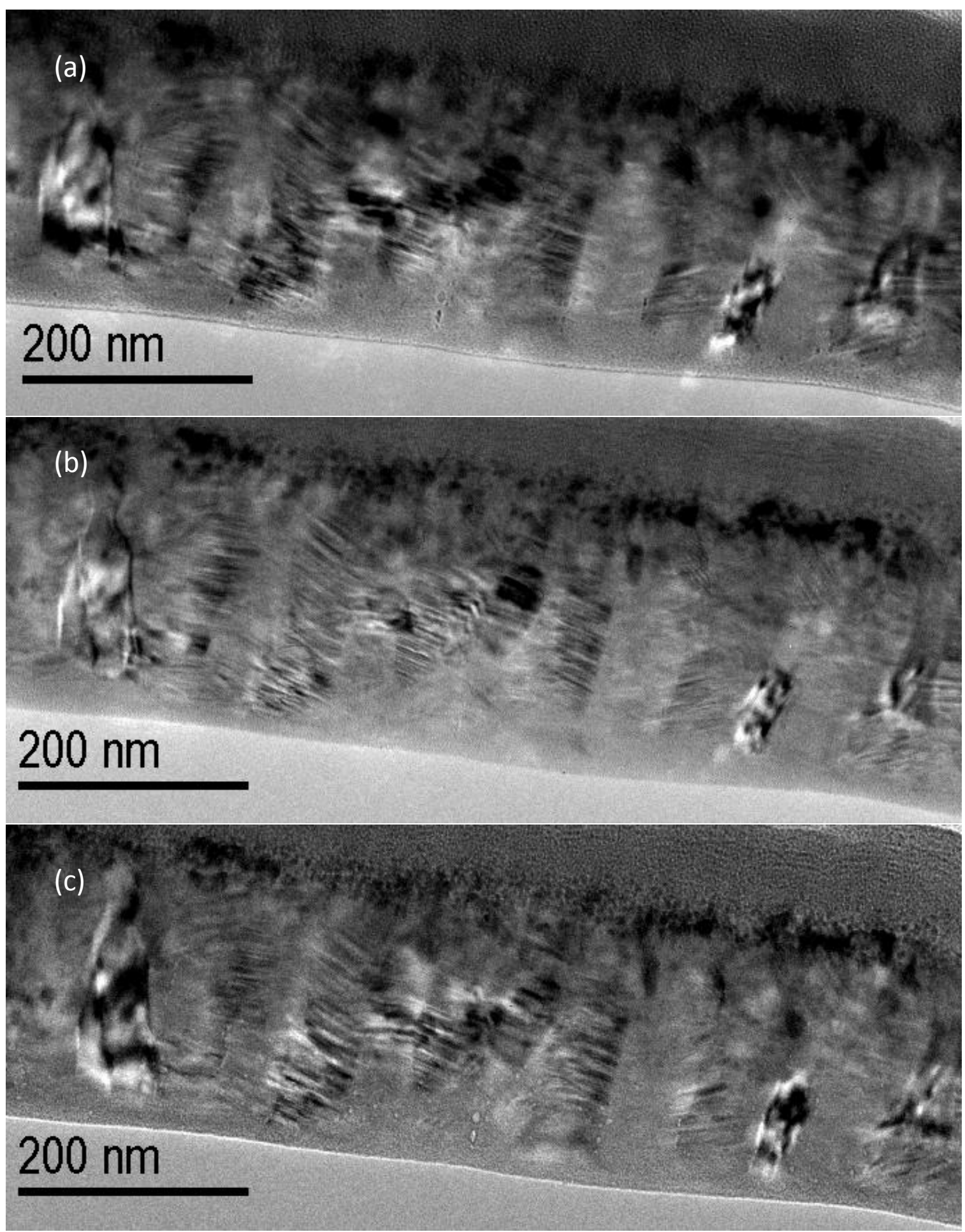

Fig. 3. Through-focus cross-sectional TEM images of NE SiC after helium implantation and post-Au irradiation to $10 \mathrm{dpa}$ at $700^{\circ} \mathrm{C}$. (a) Over-focused with defocus value of about $50 \mathrm{~nm}$, (b) in focus, and (c) under-focused with defocus value of about $50 \mathrm{~nm}$. 


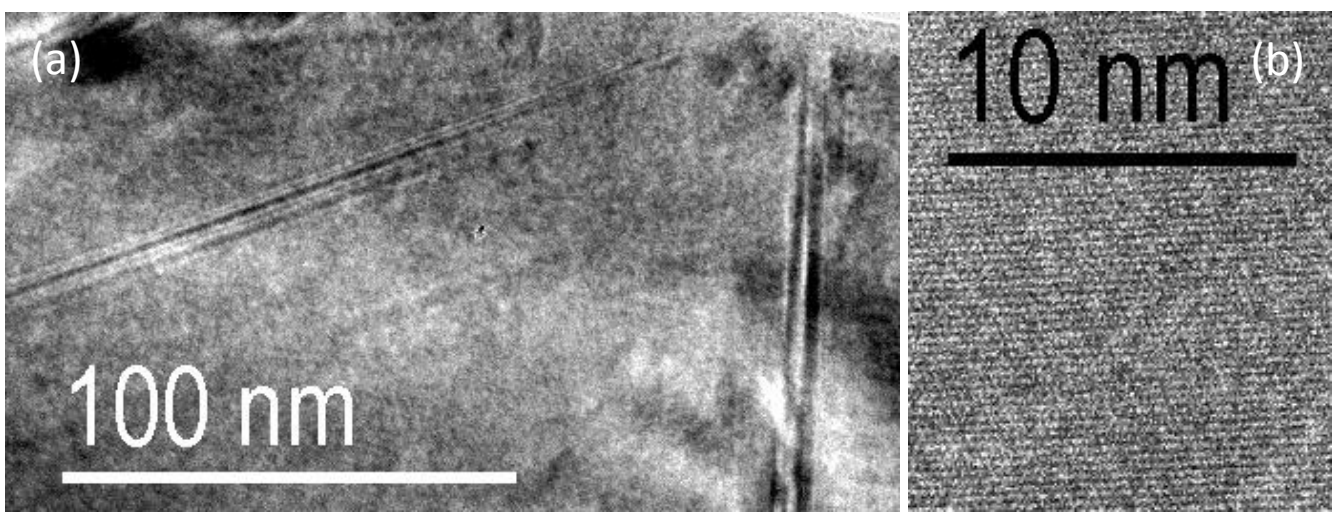

Fig. 4. (a) Cross-sectional BF TEM images of single crystal $3 \mathrm{C} \mathrm{SiC}$ after $65 \mathrm{keV} \mathrm{He}{ }^{+}$ion implantation at a fluence of $1 \times 10^{16} \mathrm{~cm}^{-2}$ at $277^{\circ} \mathrm{C}$, (b) HRTEM image acquired at $200 \mathrm{kV}$ showing the wellordered $3 \mathrm{C}$ SiC structure.

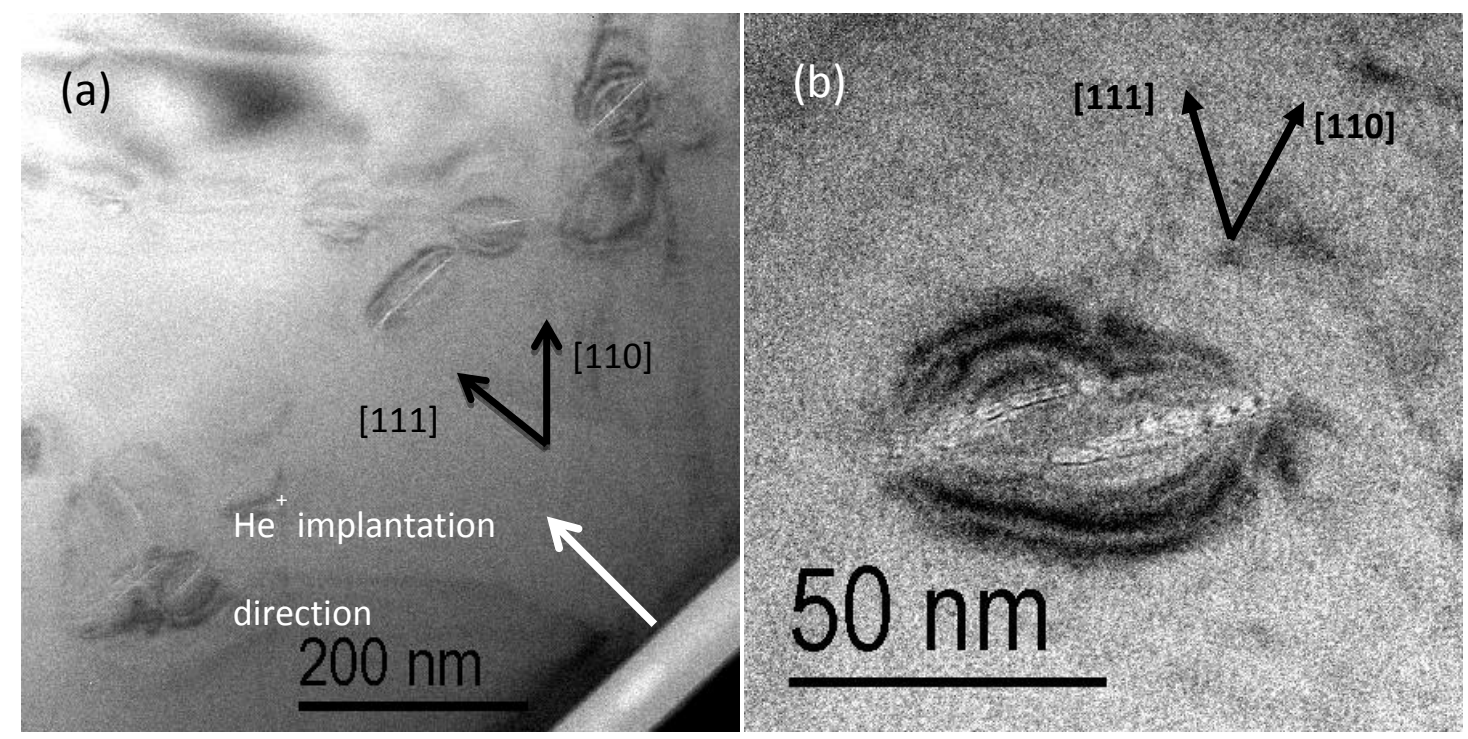

Fig. 5. (a) Cross-sectional BF TEM image showing $\{111\}$ and $\{110\}$ planar defects in heliumimplanted $3 \mathrm{C} \mathrm{SiC} \mathrm{single} \mathrm{crystal}\left(1 \times 10^{16} \mathrm{~cm}^{-2}\right)$ following thermal annealing at $700^{\circ} \mathrm{C}$ for 1 hour, and (b) Cross-sectional BF HRTEM image acquired at $200 \mathrm{kV}$ showing the planar defects in detail.
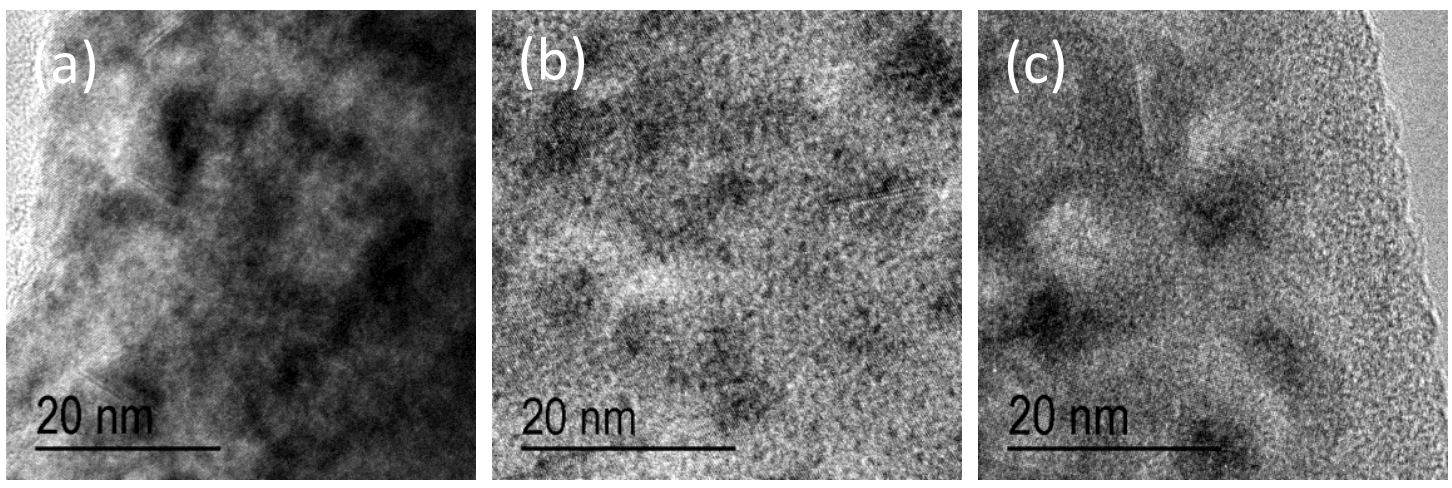

Fig. 6. Cross-sectional HRTEM images, taken at 300 to $400 \mathrm{~nm}$ from the surface (acquired at $200 \mathrm{kV}$ ), for single crystal $3 \mathrm{C} \mathrm{SiC}$ after irradiation to $10 \mathrm{dpa}$ at $700^{\circ} \mathrm{C}$ for pre-implanted helium fluences of (a) $1 \times 10^{15} \mathrm{~cm}^{-2}$, (b) $3 \times 10^{15} \mathrm{~cm}^{-2}$, and (c) $1 \times 10^{16} \mathrm{~cm}^{-2}$. 

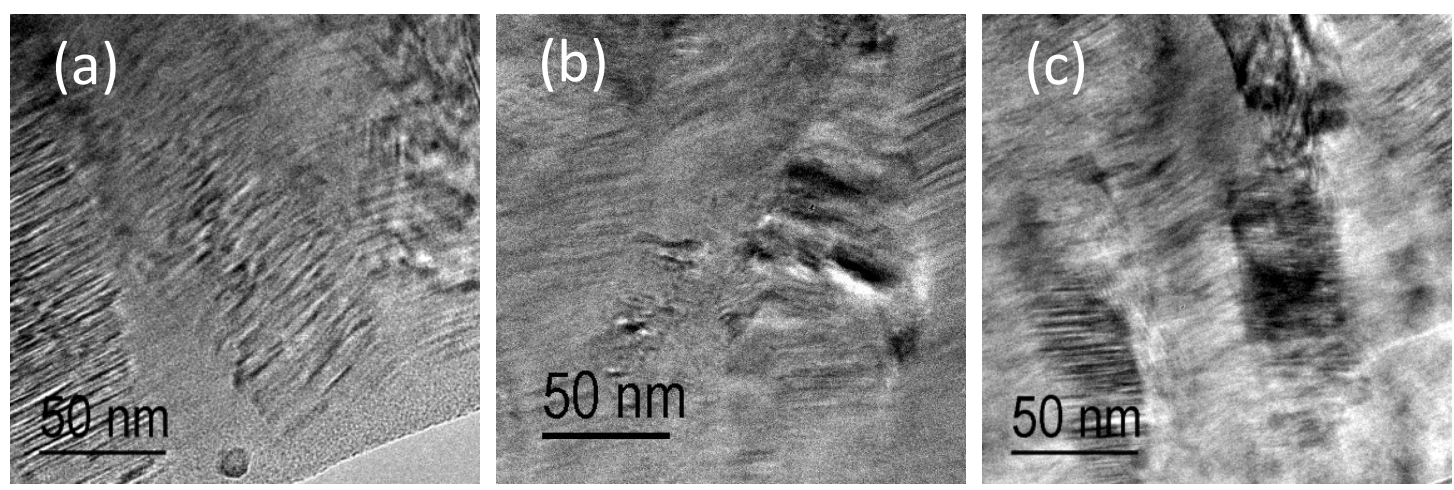

Fig. 7. Cross-sectional HRTEM images, taken at 300 to $400 \mathrm{~nm}$ from the surface (acquired at $200 \mathrm{kV}$ ), for NE SiC after helium implantation fluences of (a) $1 \times 10^{15} \mathrm{~cm}^{-2}$, (b) $3 \times 10^{15} \mathrm{~cm}^{-2}$, and (c) $1 \times 10^{16}$ $\mathrm{cm}^{-2}$.
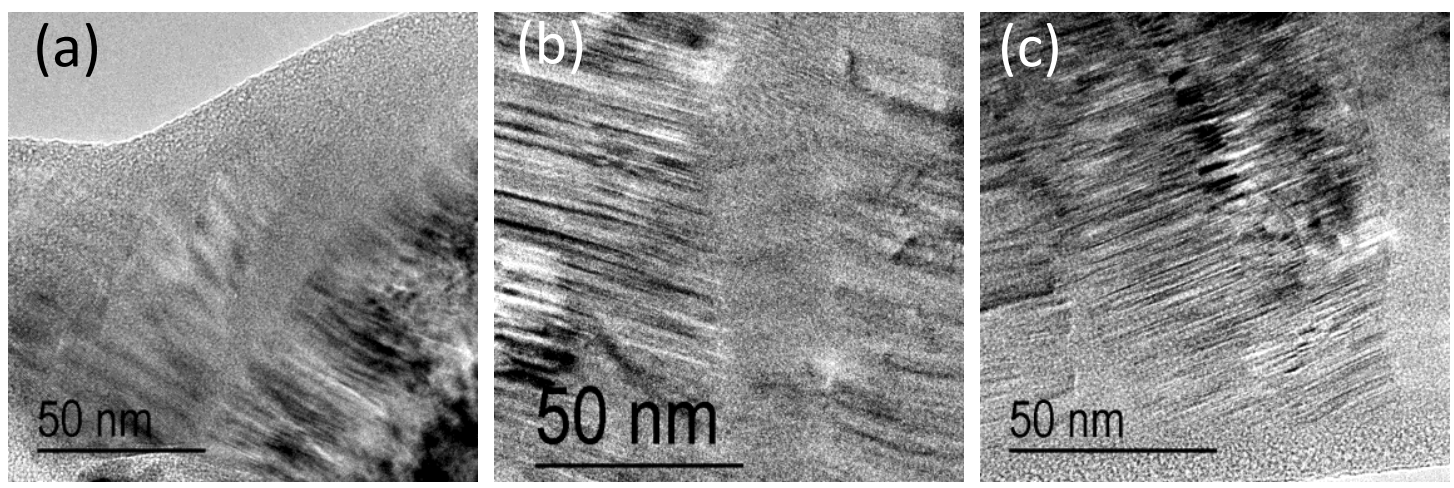

Fig. 8. Cross-sectional HRTEM images, taken at 300 to $400 \mathrm{~nm}$ from the surface (acquired at $200 \mathrm{kV}$ ), for NE SiC after $700^{\circ} \mathrm{C}$ annealing for 68 minutes for helium implantation fluences of (a) $1 \times 10^{15} \mathrm{~cm}^{-2}$, (b) $3 \times 10^{15} \mathrm{~cm}^{-2}$, and (c) $1 \times 10^{16} \mathrm{~cm}^{-2}$.
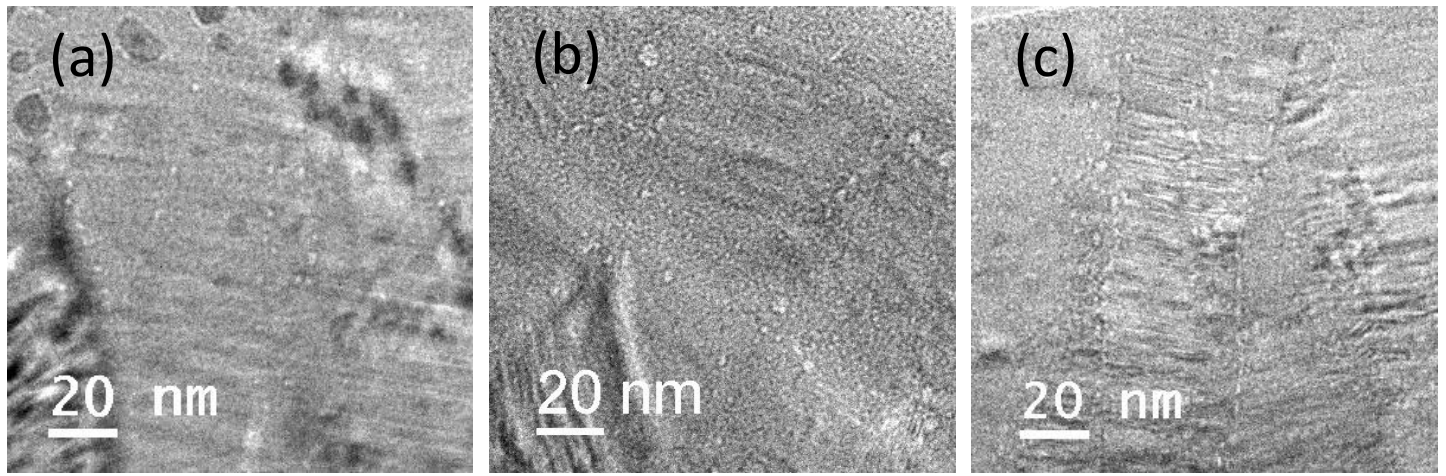

Fig. 9. Cross-sectional HRTEM images, taken at 300 to $400 \mathrm{~nm}$ from the surface (acquired at $200 \mathrm{kV}$ ), for $\mathrm{NE} \mathrm{SiC} \mathrm{after} \mathrm{Au}^{3+}$ ions irradiation to $10 \mathrm{dpa}$ at $700^{\circ} \mathrm{C}$ for helium fluence of (a) $1 \times 10^{15} \mathrm{~cm}^{-2}$, (b) $3 \times 10^{15} \mathrm{~cm}^{-2}$, and (c) $1 \times 10^{16} \mathrm{~cm}^{-2}$. 

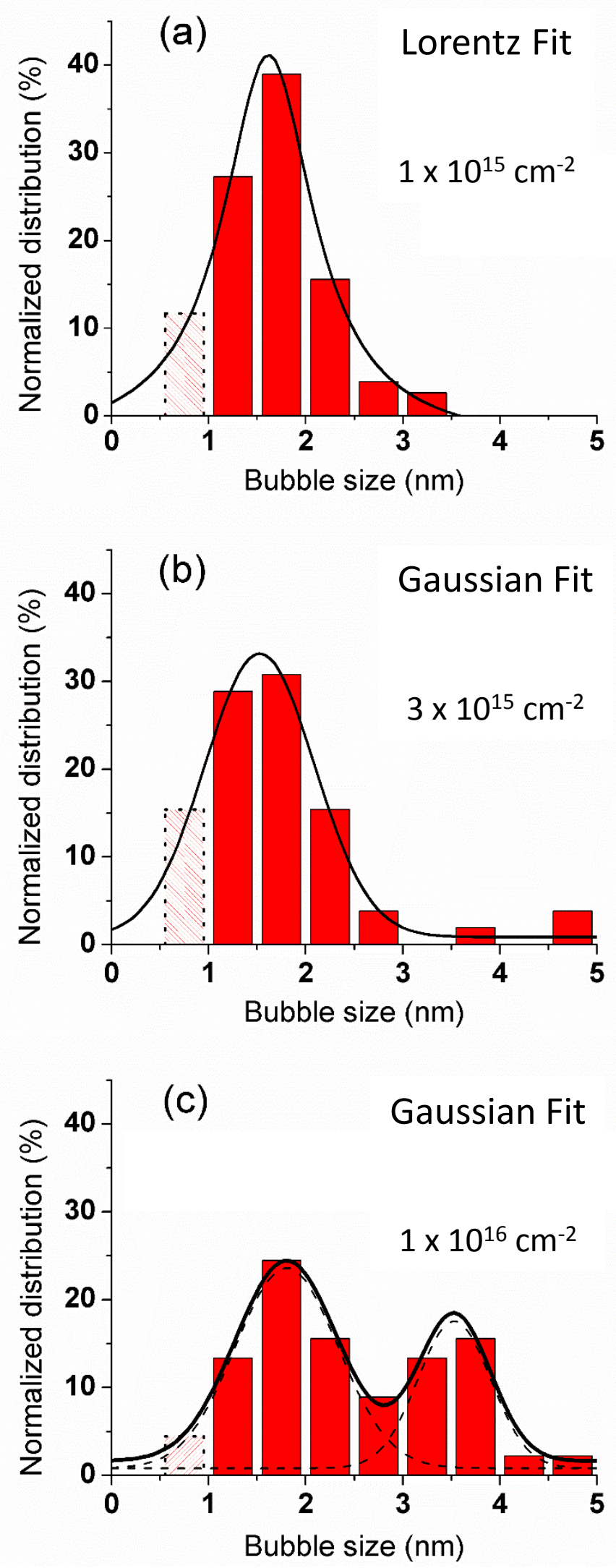

Fig. 10. Normalized bubble size distribution in NE SiC after irradiation to $10 \mathrm{dpa}$ at $700^{\circ} \mathrm{C}$ with helium fluence of (a) $1 \times 10^{15} \mathrm{~cm}^{-2}$, (b) $3 \times 10^{15} \mathrm{~cm}^{-2}$, and (c) $1 \times 10^{16} \mathrm{~cm}^{-2}$. In (c), bubbles tend to form in a bimodal distribution (black solid line), which suggests that, the He bubble aggregation is activated with increasing helium concentration under continue ion irradiation. 
Table 1.

Bubble size and density in the helium implanted NE SiC under different exposure conditions.

\begin{tabular}{|c|c|c|c|c|}
\hline \multirow{2}{*}{$\begin{array}{c}\mathrm{He} \\
\text { Fluence } \\
\left(\mathrm{cm}^{-2}\right)\end{array}$} & $\begin{array}{l}65 \mathrm{keV} \mathrm{He}^{+} \\
\text {implanted }\end{array}$ & $\begin{array}{c}\mathrm{He}^{+} \text {implanted and } \\
\text { annealed at } 700^{\circ} \mathrm{C} \text { for } 68 \\
\text { minutes }\end{array}$ & \multicolumn{2}{|c|}{$\begin{array}{c}\mathrm{He}^{+} \text {implanted and } \\
\text { subsequent } \mathrm{Au}^{3+} \text { post } \\
\text { irradiation at } 700^{\circ} \mathrm{C}(10 \\
\mathrm{dpa})\end{array}$} \\
\hline & \multicolumn{2}{|c|}{ Bubble size/ Number density } & $\begin{array}{c}\text { Bubble } \\
\text { averaged size } \\
(\mathrm{nm})\end{array}$ & $\begin{array}{c}\text { Number } \\
\text { density } \\
\left(10^{-3} / \mathrm{nm}^{2}\right)\end{array}$ \\
\hline $1 \times 10^{15}$ & Not observed & \multirow{3}{*}{$\begin{array}{l}\text { Rare cavities smaller than } \\
\qquad 1 \mathrm{~nm}\end{array}$} & $1.7 \pm 0.5$ & 1.4 \\
\hline $3 \times 10^{15}$ & \multirow{2}{*}{$\begin{array}{l}\text { Rare cavities } \\
\text { smaller than } \\
1 \mathrm{~nm}\end{array}$} & & $1.7 \pm 0.9$ & 1.3 \\
\hline $1 \times 10^{16}$ & & & $2.4 \pm 1.0$ & 1.2 \\
\hline
\end{tabular}

Table 2.

Summary of the average stacking fault spacing for NE SiC following implantation and annealing or implantation and irradiation.

\begin{tabular}{|c|c|c|}
\hline \multirow{2}{*}{$\begin{array}{c}\text { He Fluence } \\
65 \mathrm{keV} \mathrm{He}\end{array}$} & $\begin{array}{c}\mathrm{He}^{+} \text {implantation and } \\
\text { annealed at } 700^{\circ} \mathrm{C} \text { for } 68 \\
\text { minutes }\end{array}$ & $\begin{array}{c}\mathrm{He}^{+} \text {implantation and } \\
\text { subsequent } \mathrm{Au}^{3+} \text { irradiation at } \\
700^{\circ} \mathrm{C}(10 \mathrm{dpa})\end{array}$ \\
\cline { 2 - 3 } & \multicolumn{2}{|c|}{ Stacking fault spacing $(\mathrm{nm})$} \\
\hline $1 \times 10^{15}$ & 1.6 & 1.6 \\
\hline $3 \times 10^{15}$ & 1.5 & 1.8 \\
\hline $1 \times 10^{16}$ & 1.6 & 1.8 \\
\hline
\end{tabular}

